\title{
Metagenomic analysis of bacterial community composition in Dhanaan: Ethiopian traditional fermented camel milk
}

Berhe, Tesfemariam; Ipsen, Richard; Seifu, Eyassu; Kurtu, Mohamed Y; Fugl, Angelina June Brandt; Hansen, Egon Bech

\author{
Published in: \\ FEMS Microbiology Letters
}

Link to article, DOI:

10.1093/femsle/fnz128

Publication date:

2019

Document Version

Early version, also known as pre-print

Link back to DTU Orbit

Citation (APA):

Berhe, T., Ipsen, R., Seifu, E., Kurtu, M. Y., Fugl, A. J. B., \& Hansen, E. B. (2019). Metagenomic analysis of bacterial community composition in Dhanaan: Ethiopian traditional fermented camel milk. FEMS Microbiology Letters, 366(11), [fnz128]. https://doi.org/10.1093/femsle/fnz128

\section{General rights}

Copyright and moral rights for the publications made accessible in the public portal are retained by the authors and/or other copyright owners and it is a condition of accessing publications that users recognise and abide by the legal requirements associated with these rights.

- Users may download and print one copy of any publication from the public portal for the purpose of private study or research.

- You may not further distribute the material or use it for any profit-making activity or commercial gain

- You may freely distribute the URL identifying the publication in the public portal 
Metagenomic Analysis of Bacterial Community Composition in Dhanaan: Ethiopian Traditional Fermented Camel Milk

Tesfemariam Berhe ${ }^{a^{*}}$, Richard Ipsen ${ }^{b}$, Eyassu Seifu ${ }^{c}$, Mohamed Y. Kurtu ${ }^{\mathrm{a}}$, Angelina Fugl ${ }^{\mathrm{d}}$, Egon Bech Hansen $^{\mathrm{d}}$

${ }^{a}$ School of Animal and Range Sciences, Haramaya University, P.O. Box: 138, Dire Dawa, Ethiopia

${ }^{b}$ Department of Food Science, University of Copenhagen, Rolighedsvej 26, 1958 Frederiksberg C, Denmark

${ }^{c}$ Department of Food Science and Technology, Botswana University of Agriculture and Natural Resources, Private Bag: 0027, Botswana

${ }^{d}$ Division for Diet, Disease Prevention and Toxicology, National Food Institute, Technical University of Denmark, 2800 Kgs. Lyngby, Denmark

*Corresponding author:

Tesfemariam Berhe

School of Animal and Range Sciences

Haramaya University

P.O. Box: 138, Dire Dawa, Ethiopia

Phone: +251-912-029186

Fax: +251-25-553-0052

E-mail: Lucyselam@gmail.com 


\begin{abstract}
This study was conducted to evaluate the safety and bacterial profile of Dhanaan (Ethiopian traditional fermented camel milk). The composition of the microbial community in Dhanaan samples was analysed by a metagenomic approach of 16S rRNA gene amplicon sequencing. Metagenomic profiling identified 87 different bacterial microorganisms (OTUs) in six samples analysed. Although the Dhanaan samples contained various lactic acid bacteria (LAB), they also all contained undesirable microorganisms in large proportions. The following LAB genera were identified: Streptococcus, Lactococcus, and Weissella. One Streptococcus species represented by OTU-1 (operational taxonomic unit) was found in all Dhanaan samples and the dominating species in four out of six samples. This common isolate was found to be closely related to S. lutetiensis and S. infantarius. Undesirable microorganisms from genera such as Escherichia, Klebsiella,

Enterobacter, Acinetobacter and Clostridium were, however, also frequent, or even dominant in Dhanaan samples. Thus, this calls for a change in the Dahnaan manufacturing practice to an improved and safer production system. Starter cultures suitable for Dhanaan production might be developed from the Streptococcus, Weissella, and Lactococcus microorganisms identified in this study. However, further safety evaluation and technological characterization need to be conducted on strains defined by OTU-1, OTU-2, OTU-3, OTU-8, and OTU-35 before they can be used as food grade starter cultures.
\end{abstract}

Keywords: Metagenomic analysis; lactic acid bacteria; Dhanaan; OTU; fermented camel milk. 


\section{Introduction}

In many countries of dry zones of sub-Saharan Africa, camels (Camelus dromedarius) play a significant role in the lifestyle of pastoral communities owing to their adaptation to the hostile climatic conditions by providing milk, meat and transportation More than half of the world's 28 million camel population are found in the East African countries of Somalia, Sudan, Ethiopia and Kenya (FAO STAT 2014). Nowadays, the camel is attracting an increased public interest since climate change is already influencing traditional cattle productivity, whereas the camel is capable of surviving in the harsh climatic conditions (Al haj and Al Kanhal 2010; Berhe et al. 2017; El-Agamy 2006).

Pastoralists' practice and recent scientific reports indicate that fermented and fresh camel milk have therapeutic properties against different diseases (Dubey, Lal, Mittal, \& Kapur, 2015; Galil, Gader, \& Alhaider, 2016; Mati et al. 2017; Mihic et al. 2016; Seifu, 2007). Fermented camel milk is a common traditional product in several parts of the world whereas products such as butter, cheese and yoghurt are not a traditional product from camel milk (Farah et al. 2007). Fermented camel milk has different names in different parts of the world; Shubat in Turkey, Kazakhstan and Turkmenistan, Suusac/susa in Kenya and Somalia, Gariss in Sudan, Dhanaan and Ititu in Ethiopia (Farah, Mollet, Younan, \& Dahir, 2007; Seifu, 2007; Shori, 2012). Dhanaan is common in the pastoral areas of Eastern part of Ethiopia mainly in Somali and Oromia regions and Ititu is produced in the Kereyu area of Oromia region in the Eastern part of the country (Seifu, 2007; Seifu, Abraham, Kurtu, \& Yilma, 2012).

Seifu (2007) reported that pastoralists in Shinile and Jigjiga area of Eastern Ethiopia prefer to produce Dhanaan to other dairy products for its perceived high nutritional value, high demand by urban dwellers, and preference of consumers for its taste and flavour as well as long shelf life. Pastoralists in eastern Ethiopia indicated that the storage stability of Dhanaan is long and it can stay for a couples of months when accompanied with continuous back slopping, i.e., inoculating a new batch of milk with a small amounts of a previously fermented Dhanaan (Seifu, 2007). Production of Dhanaan in Eastern Ethiopia is a long tradition and made by placing unpasteurized camel milk in a smoked container, wrapping the container with a piece of cloth and keeping it at ambient temperature $\left(25^{\circ} \mathrm{C}-35^{\circ} \mathrm{C}\right)$ over extended period of time. Dhanaan has a white opaque colour, sour taste and thin consistency. It has similar appearance like cow milk Ergo (Ethiopian traditional fermented milk) but has very thin gel (Biratu and Seifu, 2016). However, it shows syneresis on storage. The pastoralists in Eastern Ethiopia claim that Dhanaan is a safe product for human consumption and has therapeutic properties. They believe that pasteurization destroys the medicinal properties of the product.

On the other hand, spontaneously fermented African camel dairy products are reported to be sources of contaminating microbes of public health concern (Biratu \& Seifu, 2016; Jans ,Bugnard, Njage, Lacroix, \& Meile, 2012). No information is available concerning the microbial profile of Dhanaan. However, similar products from other African regions have been analysed. Abdelgadir et al. (2008) analysed the microbial profile of Sudanese fermented camel milk, Gariss, and found the 
dominating LAB to be Streptococcus infantarius, Lactobacillus fermentum, Lactobacillus helveticus, and Enterococcus faecium. Jans et al. (2017) also reported that African fermented dairy products are dominated by technologically important microorganisms such as Streptococcus infantarius subsp. infantarius (Sii), Lactococcus lactis, Lactobacillus spp. and yeasts. The authors recommend the evaluation and use of the Streptococcus infantarius variants as a potential culture for future application to enhance food safety and security of the African dairy products. Safe and high quality fermented dairy products should preferably contain a microbial community dominated by lactic acid bacteria (LAB) belonging to species with a history of safe use whereas spoilage microorganisms and pathogens must be reduced to an insignificant level. LAB belonging to the genera Lactobacillus and Lactococcus are generally considered safe whereas Gram-negatives belonging to the phylum Proteobacteria are generally considered undesirable and potentially unsafe. Several LAB species of other genera than Lactococcus and Lactobacillus can contribute to quality and safety. With this study we have analysed the microbial quality of Ethiopian Dhanaan and we tried to identify $\mathrm{LAB}$ of potential use as starter cultures in order to develop safe practise for the production of Dhanaan.

\section{Materials and Methods}

\section{Sample collection and DNA extraction}

Six Dhanaan samples were collected from different market selling points ( 1 from Bombas, 2 from Gende sherka and 3 from Babile) areas in Somali and Oromia regional states of Eastern Ethiopia. Dhanaan in traditional containers is commonly sold to the customers in the areas around the streets. The samples were collected in sterilized containers and transported under ice box to Haramaya University Dairy laboratory. Samples arrived at the university lab within one hour of collection and were stored at $4{ }^{\circ} \mathrm{C}$ until DNA extraction.

Total genomic microbial DNA from the fermented milk samples were extracted using milk bacterial DNA isolation kit (Product \#21550, Norgen Biotek) according to the manufacturers' protocol. Extraction of Chromosomal DNA was done at Haramaya University Dairy laboratory, Ethiopia. The DNA concentration was measured using Qubit dsDNA assay (Qubit 3.0 Fluorometer, Q32851, Invitrogen). The extracted DNA samples were stored at $-20{ }^{\circ} \mathrm{C}$ until transported to the Technical University of Denmark for metagenomic sequencing.

\section{PCR amplification and Library preparation of the $\mathrm{V} 3$ region of the $16 \mathrm{~S}$ rRNA gene}

PCR amplification of the V3 region of 16S rRNA genes from microbial community DNA of Dhanaan samples was done as described by Laursen et al. (2016). The primers used were forward primer (PBU [primer bacterial universal] 5'A-adaptor-TCAG-barcodeCCTACGGGAGGCAGCAG-3') and reverse primer (PBR [primer bacterial reverse] 5'-trp1- 
adaptor- ATTACCGCGGCTGCTGG-3'). Both primers include sequencing adaptors. The PCR product was purified and processed for ion torrent sequencing as described in Fugl et al. (2017).

\section{DNA sequencing of $16 S$ rRNA gene libraries}

Sequencing of the prepared libraries was performed (Fugl et al. 2017) using the Ion Personal Genome Machine (PGM) with an Ion 318 chip kit (Thermo Fisher Scientific) and processed as described in Fugl et al. (2017). Briefly: sequences were analysed in CLC Genomic Workbench (version 8.5 CLC bio, Qiagen, Aarhus, Denmark). Reads were quality controlled, demultiplexed, and trimmed. Reads below $125 \mathrm{bp}$ and above $180 \mathrm{bp}$ were discarded. Operational taxonomic unit (OTU) clustering, chimera filtering, mapping of reads to OTUs, and generation of OTU table was done according to the UPARSE pipeline (Edgar 2013). The nucleotide sequences of the V3 regions of the OTUs identified was deposited at GenBank (Benson et al. 2017) with submission number SUB5459365 and accession numbers ranging from MK789774-MK789846. Taxonomy was assigned using the ribosomal database project classifier (Wang et al. 2007) with confidence threshold of 0.5 and the Greengenes database v.13.8 (DeSantis et al. 2006). Taxonomic assignments were checked by BLASTN against the $16 \mathrm{~S}$ ribosomal RNA sequences database at NCBI (national centre for biotechnology information). The relative abundance of a given taxon was calculated by considering the total number of reads in the sample.

\section{Results}

The composition of the bacterial communities of six Dhanaan samples was analysed by sequencing DNA molecules generated by PCR amplification of the V3 region of the 16S rRNA genes using universal primers. Between 20,000 and 40,000 16S rRNA V3 amplicon sequences were obtained from each sample. The sequences were assigned to a total of 87 different OTUs. Table 1 shows the relative abundance of the OTUs contributing with more than $2 \%$ in each Dhanaan sample. Table 2 lists the possible taxonomy (species assignment) of the 16 OTUs of Table 1 contributing with more than $2 \%$ of the total bacterial $16 \mathrm{~S}$ amplicon sequences in any of the Dhanaan samples. Table 3 summarizes the Key findings regarding quality and safety of the analysed Dhanaan samples. The taxonomy of the OTUs was investigated by applying a BLASTN analysis on the V3 16S rRNA sequence against the NCBI non-redundant 16S sequence database. The sequences determined for 73 of the 87 OTUs have been deposited at GenBank; 14 sequences ranging in length from 135 to 145 did not fulfil the minimum requirement of 150 set by GenBank. The results of the microbial community analysis indicate that all Dhanaan samples analysed contain microorganisms unsuitable for human consumption. One of the Dhanaan samples, sample number 6, had a microorganism belonging to the genus Escherichia as the most abundant OTU. The lowest amount of Gram-negatives was detected in sample 3 in which an Escherichia amounted to 3.9\% of the microbial community. 


\section{Discussion}

Microbial communities of the Dhanaan samples were found to be complex ecosystems with organisms belonging to the phylum Firmicutes and Proteobacteria. We found 16 OTUs to exceed 2 $\%$ in relative amount in any of the six Dhanaan samples. Ten of the 16 OTUs belong to the phylum Proteobacteria and six belong to Firmicutes.

Eight of the ten OTUs of Proteobacteria are from the family Enterobacteriaceae, representing genera like Escherichia, Klebsiella, Salmonella, Tatumella, Enterobacter, and Hafnia. The Enterobacteriaceae are indicators of poor hygiene (Quigley et al. 2013). Pathogens are common among the Enterobacteriaceae and the frequency and high level in the Dhanaan samples raise a serious health concern. Proteobacteria were also in one sample represented by two OTUs belonging to the genus Acinetobacter. Acinetobacter has not been reported to be a beneficial food culture (Bourdichon et al. 2012) and the presence of Acinetobacter is indicative of contamination from the environment probably soil (Quigley et al. 2013; Al Atrouni et al. 2016). In the sample containing Acinetobacter, the dominating organism belongs to the genus Escherichia, indicating also poor hygienic practices of the pastoralists.

The Dhanaan samples contained six OTUs belonging to the phylum Firmicutes. One of these belongs to the genus Clostridium, most likely to Clostridium tyrobutyricum. Clostridia are generally unwanted in fermented products as some clostridia are pathogenic and no clostridia have been reported to be beneficial food culture (Bourdichon et al. 2012). Clostridium tyrobutyricum is a common environmental contaminant in milk able to cause spoilage of cheese, commonly known as late blowing. The other five OTUs are lactic acid bacteria (LAB) belonging to the genera Lactococcus, Streptococcus, and Weissella.

The LAB of the Dhanaan samples might represent a potential source of starter cultures needed for a safer and improved procedure for Dhanaan manufacturing. Three of the five "lactic OTUs" belong to the genus Streptococcus. OTU-1 is the most abundant in four of the Dhanaan samples and the second most abundant in sample 1. Based on the $16 \mathrm{~S}$ sequence, OTU-1 belongs to the Streptococcus equinus complex also containing Streptococcus lutetiensis and Streptococcus infantarius. Strains belonging to this group have frequently been isolated from fermented dairy products in Africa (Abdelgadir et al. 2008; Jans et al. 2012). However, Streptococcus lutetiensis and Streptococcus infantarius have not yet been recognized as beneficial food cultures (Bourdichon et al. 2012). The dominating strain in sample 1 (defined by OTU-35) with $60 \%$ of all reads is closely related to Streptococcus sanguinis and Streptococcus cameli. Streptococcus cameli is a new species recently isolated from Morocan raw camel milk (Kadri et al. 2015) and this species does not yet have a history of use in fermented foods. The third OTU belonging to the genus Streptococcus, OTU-8, was found as a non-dominating component in two of the Dhanaan samples. The taxonomy placed this microorganism close to Streptococcus salivarius and Streptococcus thermophilus. Streptococcus thermophilus is commonly used as a starter culture for the manufacture of yoghurt (Bourdichon et al. 2012). The fourth "lactic OTU", OTU-2, was found in every Dhanaan sample in relative amounts between 2 and $28 \%$. The strain defining OUT-2 is closely related to Weissella 
cibaria and Weissella confusa. These two species have previously been found in fermented foods and they are listed in the inventory of microorganisms with beneficial use (Björkroth et al. 2002; Bourdichon et al. 2012). However, Weissella is not commonly used in starter cultures (Fessard and Remize 2017). Weissella confusa and cibaria are hetero-fermentative lactic acid bacteria and Weissella strains could therefore contribute with important flavour notes to the Dhanaan products and they might be interesting candidates to develop into Dhanaan starter cultures. The fifth "lactic OTU”, OTU-3, was identified as Lactococcus lactis. Lactococcus lactis is commonly used in starter cultures for the manufacture of cheese and fermented milk and is one of the species on the European QPS list (Bourdichon et al. 2012; Ricci et al. 2017). We can therefore conclude that this component of the Dhanaan microbiota is a beneficial component, which could also be a candidate for a Dhanaan starter culture.

Generally, the Dhanaan samples were dominated by pathogenic bacteria which have major public concern. The high content of Gram-negatives in all six Dhanaan samples analysed demonstrates that the current production practice is unsafe and needs improvement. Therefore, the pastoralists' practice of preparation of Dhanaan needs to be modified and the health issue should be considered. The pastoralists' perception towards the resistance of heat treatment of camel milk should be given a due attention in transforming the manufacturing practices to safe production. The practice of heat treatment accompanied with good manufacturing practices to avoid recontamination of the products should be implemented to produce safe and quality product. Strains of the LAB found in the Dhanaan samples that might serve as sources of starter cultures include the genus Streptococcus, Weissella, and Lactococcus which would be suitable for improved safety of Dhanaan products.

\section{Conclusion}

Metagenomic profiling showed classical and non-classical species of LAB under the genera Streptococcus, Lactococcus, and Weissella as well as unsafe microorganisms like Klebsiella, Enterobacter, Acinetobacter, and Clostridium were found in the Dhanaan samples. OTU-1 (operational taxonomic unit) was the dominating streptococcus unit in four out of six samples. This common isolate was found to be closely related to $S$. lutetiensis and $S$. infantarius. The presence of significant amount of potentially pathogenic microorganisms in the Dhanaan samples indicates the need for the transformation of the traditional practices of Dhanaan manufacturing to an improved and safer production system. LAB species under OTU-1, OTU-2, OTU-3, OTU-8, and OTU-35 might be technologically important lactic acid bacteria for the fermentation of camel dairy products. However, further safety evaluation and characterization need to be conducted on such species before being considered as food grade bacteria. 


\section{Funding}

This work was supported by Danish International Development Agency (Danida) "through Haramaya Camel Dairy Project”; (grant number 12-017DTU).

\section{Acknowledgments}

We want to express our great thanks to Danish International Development Agency (Danida) for funding "Haramaya Camel Dairy Project". The partners of the project were the Technical University of Denmark, University of Copenhagen (Denmark), Chr. Hansen A/S (Denmark) and Haramaya University (Ethiopia).

\section{Conflict of interest}

The authors declare that there is no conflict of interest 


\section{References}

Abdelgadir W, Nielsen DS, Hamad S et al. A traditional Sudanese fermented camel's milk product, Gariss, as a habitat of Streptococcus infantarius subsp. infantarius. Int J Food Microbiol 2008;127:215-9.

Al Atrouni A, Joly-Guillou M-L, Hamze M et al. Reservoirs of Non-baumannii Acinetobacter Species. Front Microbiol 2016;7:49.

Al haj OA, Al Kanhal HA. Compositional, technological and nutritional aspects of dromedary camel milk. Int Dairy J 2010;20:811-21.

Benson DA, Cavanaugh M, Clark K et al. GenBank. Nucleic Acids Res 2017;45:D37-42.

Berhe T, Seifu E, Ipsen R et al. Processing Challenges and Opportunities of Camel Dairy Products. Int J Food Sci 2017;2017:1-8.

Biratu K, Seifu E. Chemical composition and microbiological quality of Dhanaan : traditional fermented camel milk produced in eastern Ethiopia. Int Food Res $J$ 2016;23:2223-8.

Björkroth KJ, Schillinger U, Geisen R et al. Taxonomic study of Weissella confusa and description of Weissella cibaria sp. nov., detected in food and clinical samples. Int J Syst Evol Microbiol 2002;52:141-8.

Bourdichon F, Casaregola S, Farrokh C et al. Food fermentations: Microorganisms with technological beneficial use. Int J Food Microbiol 2012;154:87-97.

DeSantis TZ, Hugenholtz P, Larsen N et al. Greengenes, a chimera-checked 16S rRNA gene database and workbench compatible with ARB. Appl Environ Microbiol 2006;72:5069-72.

Dubey U, Lal M, Mittal A et al. Therapeutic potential of camel milk. Emirates J Food Agric 2015;28:164-76.

Edgar RC. UPARSE: highly accurate OTU sequences from microbial amplicon reads. Nat Methods 2013;10:996-8.

El-Agamy EI. camel milk. In: Park YW, G.F.W. Haenlein (eds.). Handbook of Milk of Non-Bovine Mammals. 1st ed. Blackwell Publishing, 2006, 297.

FAO STAT. Faostat3.Fao.Org/., 2014.

Farah Z, Mollet M, Younan M et al. Camel dairy in Somalia: Limiting factors and development potential. Livest Sci 2007;110:187-91.

Fessard A, Remize F. Why Are Weissella spp. Not Used as Commercial Starter Cultures for Food Fermentation? Fermentation 2017;3:38.

Fugl A, Berhe T, Kiran A et al. Characterisation of lactic acid bacteria in spontaneously fermented camel milk and selection of strains for fermentation of camel milk. Int Dairy J 2017;73:19-24.

Galil A, Gader MA, Alhaider AA. The unique medicinal properties of camel products : A review of 
the scientific evidence. J Taibah Univ Med Sci 2016;11:98-103.

Jans C, Bugnard J, Njage PMK et al. Lactic acid bacteria diversity of African raw and fermented camel milk products reveals a highly competitive, potentially health-threatening predominant microflora. LWT - Food Sci Technol 2012;47:371-9.

Jans C, Meile L, Kaindi DWM et al. African fermented dairy products - Overview of predominant technologically important microorganisms focusing on African Streptococcus infantarius variants and potential future applications for enhanced food safety and security. Int J Food Microbiol 2017;250:27-36.

Kadri Z, Vandamme P, Ouadghiri M et al. Streptococcus tangierensis sp. nov. and Streptococcus cameli sp. nov., two novel Streptococcus species isolated from raw camel milk in Morocco. Antonie van Leeuwenhoek, Int J Gen Mol Microbiol 2015;107:503-10.

Laursen MF, Andersen LBB, Michaelsen KF et al. Infant Gut Microbiota Development Is Driven by Transition to Family Foods Independent of Maternal Obesity. Am Soc Microbiol 2016;1:116.

Mati A, Senoussi-ghezali C, Si S et al. Dromedary camel milk proteins, a source of peptides having biological activities e A review. Int Dairy J 2017;73:25-37.

Mihic T, Rainkie D, Wilby KJ et al. The Therapeutic Effects of Camel Milk : A Systematic Review of Animal and Human Trials. J Evid Based Complementary Altern Med 2016;21:110-26.

Quigley L, O'Sullivan O, Stanton C et al. The complex microbiota of raw milk. FEMS Microbiol Rev 2013;37:664-98.

Ricci A, Allende A, Bolton D et al. Scientific Opinion on the update of the list of QPSrecommended biological agents intentionally added to food or feed as notified to EFSA * . 2017;15, DOI: 10.2903/j.efsa.2017.4664.

Seifu E. Handling, preservation and utilization of camel milk and camel milk products in Shinile and Jijiga Zones, eastern Ethiopia. Livest Res Rural Dev 2007;19.

Seifu E, Abraham A, Kurtu MY et al. Isolation and characterization of lactic acid bacteria from Ititu : Ethiopian traditional fermented camel milk. J Camelid Sci 2012:82-98.

Shori AB. Comparative study of chemical composition, isolation and identification of micro-flora in traditional fermented camel milk products: Gariss, Suusac, and Shubat. J Saudi Soc Agric Sci 2012;11:79-88.

Wang Q, Garrity GM, Tiedje JM et al. Naive Bayesian classifier for rapid assignment of rRNA sequences into the new bacterial taxonomy. Appl Environ Microbiol 2007;73:5261-7. 
Table 1: Relative abundance of OTUs present in amounts larger than $2 \%$ of the total bacterial communities in the Dhanaan samples

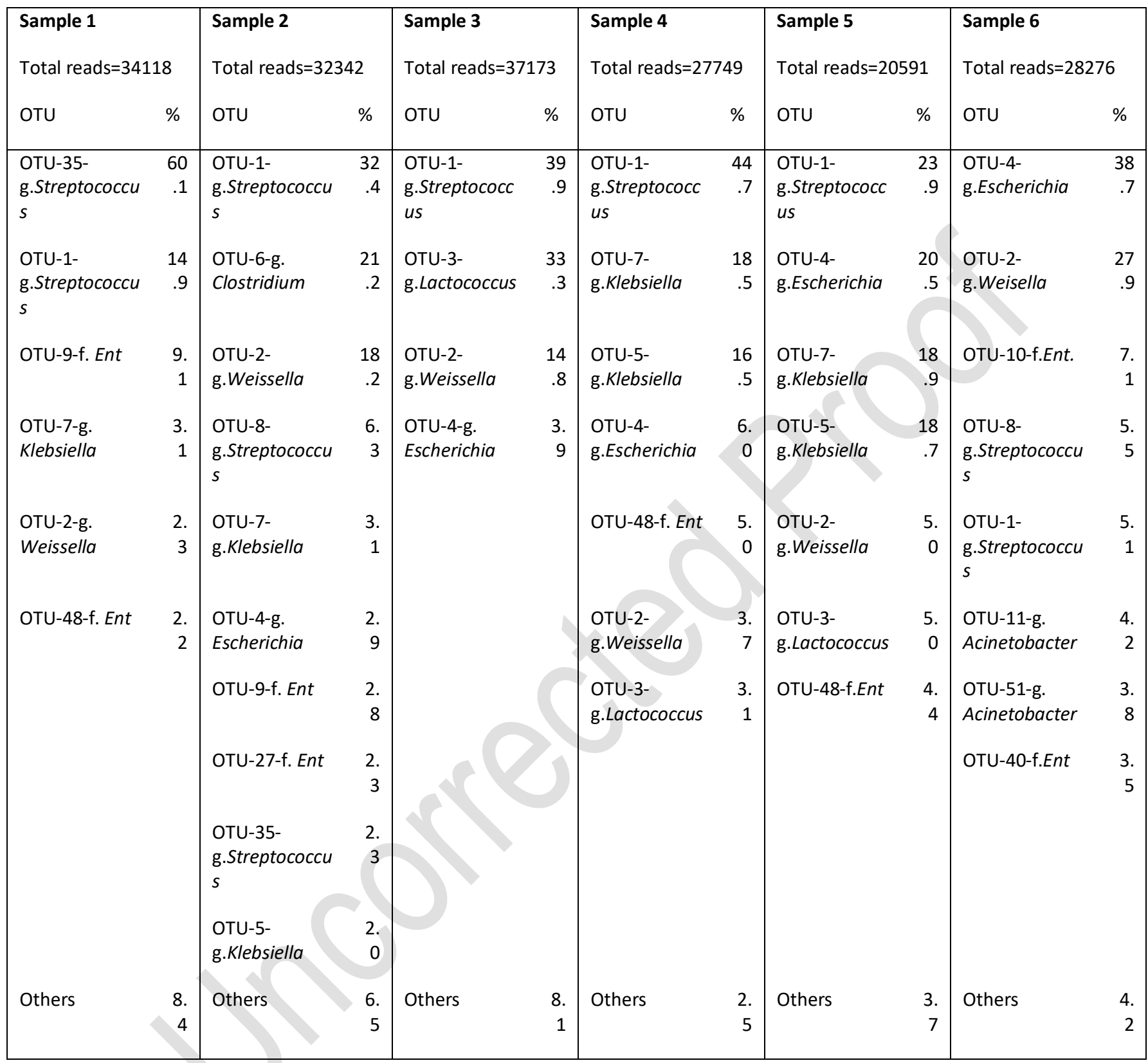

OTU, operational taxonomic unit; Ent, Enterobacteriaceae; $\mathrm{g}$ and $\mathrm{f}$ indicate identification at genus and family level, respectively. Sample 1 (Bombas); Sample 2 and 3 (Gende sherka); Sample 4, 5 and 6 (Babile) 
Table 2: Taxonomy of abundant OTUs found in Dhanaan samples

\begin{tabular}{|c|c|c|c|c|c|}
\hline OTU & accession \# & Genus & species & Accession \# & \% Identity \\
\hline \multirow[t]{8}{*}{ OTU-1-g.Streptococcus } & MK789774 & Streptococcus & alactolyticus & NR_041781 & 100 \\
\hline & & & danieliae & NR_117375 & 100 \\
\hline & & & equinus & $\begin{array}{l}\text { NR_113594, } \\
\text { NR_114642, } \\
\text { NR_042052 }\end{array}$ & 100 \\
\hline & & & lutetiensis & $\begin{array}{l}\text { NR_115719, } \\
\text { NR_037096, } \\
\text { NR_042051 }\end{array}$ & 100 \\
\hline & & & macedonicus & NR_037002 & 100 \\
\hline & & & pasteurianus & NR_043660 & 100 \\
\hline & & & porcorum & NR_108477 & 99 \\
\hline & & & infantarius & NR_104991 & 99 \\
\hline \multirow[t]{2}{*}{ OTU-2-g.Weissella } & MK789775 & Weissella & cibaria & NR_036924 & 100 \\
\hline & & & confusa & $\begin{array}{l}\text { NR_113258, } \\
\text { NR_040816 }\end{array}$ & 100 \\
\hline \multirow[t]{2}{*}{ OTU-3-g.Lactococcus } & MK789776 & Lactococcus & lactis & $\begin{array}{l}\text { NR_116443, } \\
\text { NR_113958, } \\
\text { NR_040956, } \\
\text { NR_113925, } \\
\text { NR_040954, } \\
\text { NR_113960, }\end{array}$ & 100 \\
\hline & & & & NR_040955 & \\
\hline \multirow[t]{8}{*}{ OTU-4-g.Escherichia } & MK789777 & Brenneria & alni & NR_116340 & 100 \\
\hline & & Escherichia & albertii & NR_025569 & 100 \\
\hline & & & coli & $\begin{array}{l}\text { NR_114042, } \\
\text { NR_112558 }\end{array}$ & 100 \\
\hline & & & fergusonii & $\begin{array}{l}\text { NR_074902, } \\
\text { NR_114079, } \\
\text { NR_027549 }\end{array}$ & 100 \\
\hline & & & vulneris & NR_119109 & 100 \\
\hline & & Shigella & dysenteriae & NR_026332 & 100 \\
\hline & & & flexneri & NR_026331 & 100 \\
\hline & & & sonnei & NR_104826 & 100 \\
\hline
\end{tabular}




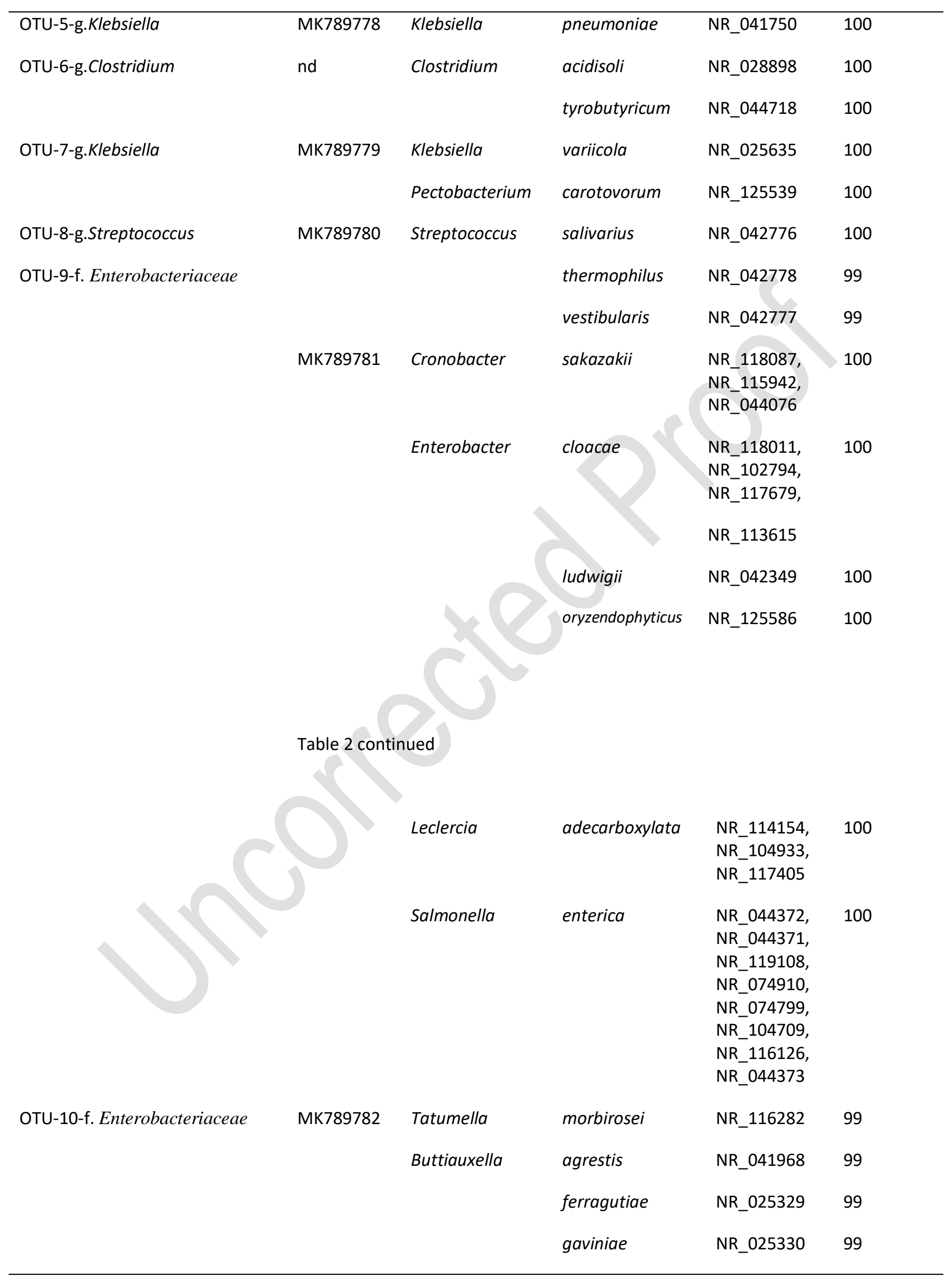




\begin{tabular}{|c|c|c|c|c|c|}
\hline & & & noackiae & NR_036919 & 99 \\
\hline & & Kluyvera & intermedia & $\begin{array}{l}\text { NR_114153, } \\
\text { NR_028802, } \\
\text { NR_112007 }\end{array}$ & 99 \\
\hline OTU-11-g. Acinetobacter & MK789783 & Acinetobacter & albensis & NR_145641 & 99 \\
\hline \multirow[t]{5}{*}{ OTU-27-f. Enterobacteriaceae } & MK789797 & Enterobacter & hormaechei & NR_042154 & 99 \\
\hline & & & tabaci & NR_146667 & 99 \\
\hline & & & mori & NR_116430 & 99 \\
\hline & & Shimwellia & blattae & $\begin{array}{l}\text { NR_074908, } \\
\text { NR_116602, } \\
\text { NR_116478 }\end{array}$ & 99 \\
\hline & & Cronobacter & malonaticus & NR_044060 & 99 \\
\hline \multirow[t]{2}{*}{ OTU-35-g.Streptococcus } & MK789805 & Streptococcus & cameli & NR_134817 & 99 \\
\hline & & & sanguinis & $\begin{array}{l}\text { NR_113260, } \\
\text { NR_024841, } \\
\text { NR_111994 }\end{array}$ & 99 \\
\hline \multirow[t]{7}{*}{ OTU-40-f. Enterobacteriaceae } & MK789808 & Hafnia & alvei & $\begin{array}{l}\text { NR_044729, } \\
\text { NR_112985 }\end{array}$ & 99 \\
\hline & & Obesumbacterium & proteus & NR_025334 & 99 \\
\hline & & Buttiauxella & warmboldiae & NR_028893 & 99 \\
\hline & & & izardii & NR_025331 & 99 \\
\hline & & & brennerae & NR_025328 & 99 \\
\hline & & Lelliottia & nimipressuralis & NR_044976 & 99 \\
\hline & & & amnigena & NR_024642 & 99 \\
\hline \multirow{5}{*}{ OTU-48-f. Enterobacteriaceae } & MK789815 & Enterobacter & cloacae & NR_118568 & 99 \\
\hline & & & xiangfangensis & NR_126208 & 99 \\
\hline & & & asburiae & NR_024640 & 99 \\
\hline & & Erwinia & billingiae & NR_104932 & 99 \\
\hline & & Klebsiella & $a l b a$ & NR_132596 & 99 \\
\hline \multirow[t]{2}{*}{ OTU-51-g. Acinetobacter } & MK789818 & Acinetobacter & pittii & $\begin{array}{l}\text { NR_117621, } \\
\text { NR_117930, } \\
\text { NR_116774 }\end{array}$ & 100 \\
\hline & & & calcoaceticus & NR_042387 & 100 \\
\hline
\end{tabular}

OTU, operational taxonomic unit; $g$ and $\mathrm{f}$ indicate identification at genus and family level, respectively 
${ }^{\mathrm{a}}$ Accession \# are for deposits in Genbank.

Nd; not deposited. 
Table 3: Key findings regarding quality and safety of Dhanaan samples analysed

\begin{tabular}{ll}
\hline Positively affecting Dhanaan quality & Negatively affecting safety of Dhanaan \\
\hline $\begin{array}{l}\text { All six samples contain LAB in which OTU-1 } \\
\text { (operational taxonomic unit) was the dominating } \\
\text { streptococcus unit in four out of six samples. This } \\
\text { common isolate was found to be closely related to }\end{array}$ & $\begin{array}{l}\text { All six samples contain Gram negative } \\
\text { microorganisms }\end{array}$ \\
$\begin{array}{ll}S . \text { lutetiensis and } S \text {. infantarius } \\
\text { Fraction of LAB range from 50 to 90\% of the } \\
\text { microbiota }\end{array}$ & $\begin{array}{l}\text { Fraction of Gram negatives range from } \\
\text { 4 to } 60 \% \text { of the microbiota }\end{array}$ \\
$\begin{array}{l}\text { LAB could be a source of safe starter cultures } \\
\text { specific for camel milk fermentation }\end{array}$ & $\begin{array}{l}\text { In one Dhanaan sample, Escherichia is } \\
\text { the most frequent microorganism }\end{array}$ \\
& $\begin{array}{l}\text { Safety of the LAB present in Dhanaan } \\
\text { needs to be investigated further }\end{array}$ \\
\hline
\end{tabular}

